NBER WORKING PAPER SERIES

GROWTH, AUTOMATION AND THE LONG RUN SHARE OF LABOR

Debraj Ray I Dilip Mookherjee

Working Paper 26658

http://www.nber.org/papers/w26658

NATIONAL BUREAU OF ECONOMIC RESEARCH

1050 Massachusetts Avenue

Cambridge, MA 02138

January 2020

Mookherjee thanks the Department of Economics at NYU for hosting his visit in Fall 2017 when this project was started. Ray acknowledges funding from the National Science Foundation under grant SES-1851758. We are grateful to Pascual Restrepo for useful conversations, and Erik Madsen for a proof of Lemma A2 in the Supplementary Appendix. Author names are in random order. The views expressed herein are those of the authors and do not necessarily reflect the views of the National Bureau of Economic Research.

NBER working papers are circulated for discussion and comment purposes. They have not been peer-reviewed or been subject to the review by the NBER Board of Directors that accompanies official NBER publications.

(C) 2020 by Debraj Ray (r) Dilip Mookherjee. All rights reserved. Short sections of text, not to exceed two paragraphs, may be quoted without explicit permission provided that full credit, including $\odot$ notice, is given to the source. 
Growth, Automation and the Long Run Share of Labor

Debraj Ray P Dilip Mookherjee

NBER Working Paper No. 26658

January 2020

JEL No. D33,E25,J24,J31,O33

\begin{abstract}
$\underline{\text { ABSTRACT }}$
We provide an argument for long-term automation and decline in the labor income share, driven by capital accumulation rather than technical progress or rising markups. We emphasize a fundamental asymmetry across physical and human capital. An individual can indefinitely replicate her claims on the former, but - after a point - her human endowment cannot be cloned and rescaled in the same way. Then ongoing capital accumulation gives rise to progressive automation, and the share of labor income converges to zero. The displacement of human labor is gradual, and real wages could rise indefinitely. The results extend to endogenous technical change.
\end{abstract}

\author{
Debraj Ray \\ Department of Economics \\ New York University \\ 19 West Fourth Street \\ New York, NY 10003 \\ and University of Warwick \\ and also NBER \\ debraj.ray@nyu.edu \\ Dilip Mookherjee \\ Department of Economics \\ Boston University \\ 270 Bay State Road \\ Boston, MA 02215 \\ and NBER \\ dilipm@bu.edu
}

A data appendix is available at http://www.nber.org/data-appendix/w26658 


\title{
Growth, Automation and the Long Run Share of Labor*
}

\author{
Debraj Ray (r) Dilip Mookherjee
}

December 2019

\begin{abstract}
We provide an argument for long-term automation and decline in the labor income share, driven by capital accumulation rather than technical progress or rising markups. We emphasize a fundamental asymmetry across physical and human capital. An individual can indefinitely replicate her claims on the former, but - after a point her human endowment cannot be cloned and rescaled in the same way. Then ongoing capital accumulation gives rise to progressive automation, and the share of labor income converges to zero. The displacement of human labor is gradual, and real wages could rise indefinitely. The results extend to endogenous technical change.
\end{abstract}

\section{INTRODUCTION}

The growing evidence worldwide for a declining labor share in national income (Karabarbounis and Neiman 2014, Piketty 2014) — thereby dismantling a central "Kaldor fact" — has generated active debate and research. ${ }^{1}$ Explanations in terms of capital-labor substitution along some aggregate CES production function are problematic: substitution elasticities need to exceed one, which is rejected by panel studies of industry level production functions (Chirinko and Mallick 2014). Other arguments include globalization, whereby labor in developed countries are devastated by cheap imports (Autor, Dorn and Hansen 2016), selection into more profitable and therefore higher-markup firms (Autor et al 2017), factors such as the rise of the gig economy or greater product differentiation,

\footnotetext{
*Mookherjee: Boston University; Ray: New York University and University of Warwick. Mookherjee thanks the Department of Economics at NYU for hosting his visit in Fall 2017 when this project was started. Ray acknowledges funding from the National Science Foundation under grant SES-1851758. We are grateful to Pascual Restrepo for useful conversations, and Erik Madsen for a proof of Observation A.2 in the Supplementary Appendix. Author names are in random order.

${ }^{1}$ Piketty's " $r>g$ " theory has been criticized, given its compatibility with a variety of standard growth models exhibiting no decline in labor share (Acemoglu and Robinson 2015, Mankiw 2015, Ray 2015).
} 
leading to a decline in firm competition and the bargaining power of labor (Neary 2003, Gutiérrez and Philippon 2017, Azar and Vives 2018, and Eggertsson, Robbins, and Wold 2018), and certainly the possibility of technical progress that favors automation (Santens 2016, Acemoglu and Restrepo 2019, Aghion, Jones and Jones 2019).

These explanations have useful roles to play in explaining or at least describing the phenomenon of a falling labor share, but do not seem to tell the full story. For instance, globalization cannot explain why we see a similar decline in labor share or a greater awareness of "jobless growth" in countries such as China and India. Factors such as greater industrial concentration or a decline in bargaining power are possibly endogenous outcomes of rising automation and technical progress. Even technical progress seems an insufficient explanation - Karabarbounis and Neiman (2014) show that a substantial fraction of the decline in labor share worldwide is explained by declining capital good prices, even after controlling for capital-augmenting technical progress, markup rates and the skill composition of the labor force.

Our paper, while partly motivated by these observations, serves a more primitive purpose. We argue that the benchmark growth model, with balanced growth at its core, needs re-examination. That is, growth accompanied by the possibility of progressive automation must be a central feature of any model which recognizes a basic asymmetry - to be developed below - between physical and human capital accumulation. Certainly, that baseline model can be augmented by endogenous technical progress (we will do so), or by other features such as industrial concentration or increasing product differentiation. But the failure of the central Kaldor "fact" is directly predicted by any benchmark model which builds in the following five features:

(I) Growth. Physical capital per-capita is (on average) consistently accumulated over time. Standard conditions on underlying parameters such as time preferences relative to technology suffice to generate this outcome.

(II) Asymmetry. There is a fundamental asymmetry between an individual's accumulation of human capital, and her accumulation of claims to physical capital. Specifically, 
the latter is duplicable in a way that the former isn't. Physical capital (and claims on it) can be replicated to an unbounded degree. But the same is not true of human capital - after a point, it has to do with the acquisition of skills that enable entry into possibly related but distinct occupations or sectors, not a sustained scaling-up within the same occupation. In short, an individual cannot turn an endowment of, say, one bank manager into two, three, four ... bank managers, ${ }^{2}$ In contrast, an endowment of one machine can be grown into two, three, four ... machines, so claims on capital can be replicated and expanded "in natural units" in a way that a labor endowment cannot. ${ }^{3}$

This presumed asymmetry stands in contrast to a long tradition (Uzawa 1961, Becker and Tomes 1979, Loury 1981, Lucas 1988, Mankiw, Romer and Weil 1992), in which human and physical capital are modeled as symmetric engines of accumulation. Under this view, both are driven by some aggregative dynamic process which can scale up individual endowments in "efficiency units" to arbitrarily large degrees. The following pair of equations from Mankiw, Romer and Weil (1992, p. 416) exemplify this point:

$$
\begin{aligned}
& \dot{k}(t)=s_{k} y(t)+(n+g+\delta) k(t) \\
& \dot{h}(t)=s_{h} y(t)+(n+g+\delta) h(t),
\end{aligned}
$$

where the variables are self-explanatory. Such symmetry may be a convenient way to obtain steady states or balanced growth. But the recent facts belie this presumption. ${ }^{4}$

(III) Machines and Robots. Physical capital complements human labor in some respects (we call such capital machines) and substitutes for it in others (we call such capital robots). Of course, most capital goods have a bit of machine and a bit of robot in them.

\footnotetext{
${ }^{2}$ We are not referring here to technical progress which raises effective productivity of humans within a particular sector. That is different from an individual accumulating an ever-larger labor endowment in natural units for the same job.

${ }^{3}$ Like human capital, physical capital can move over a large number of different sectors, and could have sector-specific characteristics. The point is that it can also scale up within a sector.

${ }^{4}$ Mookherjee and Ray $(2002,2003,2010)$ also argue that by lumping different occupational choices into homogeneous efficiency units, much of this literature misses the endogenous movements in relative prices that lie at the heart of persistent inequality.
} 
We assume that in every sector, there is scope for replacing humans by robots, if the price is right. Certainly, there are sectors where humans are protected, and sectors where they are vulnerable, but in every sector humans can be challenged by robots, and will be replaced if the ratio of human wages to robot capital is large enough. As Scott Santens writes in the Boston Globe, 2016: "nothing humans do as a job is uniquely safe anymore. From hamburgers to healthcare, machines can be created to successfully perform such tasks with no need or less need for humans, and at lower costs than humans..." Observe that this is a different view from one that argues that technical progress will render humans obsolete. That may or may not be true, a question we pursue later in the paper.

(IV) Singularity. Turning to robot production, it is obvious that the price of robot services will be sandwiched between those of machine capital and the wages of technicians, engineers and researchers active in the robot-producing sector. A crucial question that bears on automation is whether robot prices will be tied more closely to human wages or to the price of capital in the robot producing sector as capital continues to accumulate. We argue that a "singularity condition" determines the answer to this question. It is connected to the eventual automation of the robot sector itself. ${ }^{5}$ If that condition placed on the robot sector alone, involving the elasticity of substitution within that sector relative to the effectiveness of humans vis-a-vis robots - is satisfied, ${ }^{6}$ the price of robots must eventually become tied to that of machine capital (Proposition 1).

(V) Preference Neutrality. The structure of household demand has no built-in bias in favor of — or against — sectors in which human labor have a comparative disadvantage

\footnotetext{
${ }^{5}$ The idea of such a singularity appears to have been first envisaged by von Neumann in his work on self-reproducing automata; see von Neumann and Burns (1966). The idea reappears in recent economic literature: for instance, Aghion, Jones and Jones (2019) discuss singularities in the production of ideas, in a setting with exogenous rates of automation.

${ }^{6}$ The singularity condition compares the elasticity of substitution between capital and (human or robot) labor with the efficiency of robots relative to humans in providing labor. It is automatically met if the former elasticity equals or exceeds 1 , but is also consistent with sub-unitary elasticities of substitution. Note that while the singularity condition has economy-wide ramifications, it is a condition on the robot sector alone — we place no restriction on substitution elasticities in any other sector.
} 
relative to robots. We will assume nothing about underlying preferences when there is a finite number of final goods sectors, and presume that preferences are asymptotically homothetic (for large incomes) when there are infinitely many such sectors. So the growth in per capita incomes does not (at any given set of relative prices) tilt demand in any particular direction, though certainly demands are responsive to prices. We also discuss what happens when such neutrality fails.

These five ingredients together imply that a growing economy has no long-run steady state that includes human labor; specifically, the long-run income share of human labor must converge to zero. This occurs via progressive automation - every "consequential sector" that grows along with national income must ultimately fall prey to automation. We emphasize that this result is intrinsic to a very basic growth model and has nothing to do with technical progress, markups, product differentiation, etc. See Theorems 1, 2, and 4, which cover different cases under which the same result holds, and Theorem 3 that guarantees sufficient conditions for continued growth in the economy.

It also bears emphasis that ours is a result about the share of labor in national income. A declining labor share is perfectly compatible with increasing absolute wages — indeed, even unboundedly increasing wages; see for instance part (iii) of Theorem 2. After all, provisionally accepting our assertion regarding widespread automation, it has to be the case that human wages must rise so as to generate incentives for the more humanfriendly sectors to be automated in the first place. Moreover, our results are about the functional share of labor. With more structure on the distribution of preferences, this functional share can be translated into a statement about personal income distribution — and the model is potentially equipped to do this — but that is not our focus here.

There are three escape routes from this scenario. The first has to do with the failure of the singularity condition, in which case rising human wages do not automatically generate automation. The second has to do with a particular structure of preferences. If preferences are non-homothetic, but not just that, they are non-homothetic in a particular direction - one that lines up with ever greater "human-friendliness" in production (we need an infinite number of sectors to formalize this idea) then it is possible to envisage a 
future where human labor perpetually retains a positive share of income. With growth, humans would progressively move to these friendly sectors, and by the assumed nonhomotheticity of preferences, there would be adequate demand for such products.

The third escape hatch has to do with systematic asymmetries in the opportunities for technical progress - biases that favor the use of human labor. We would then have to assume those asymmetries, and their relative impact would be an empirical question. The recent contribution by Acemoglu and Restrepo (2018) is a leading example of this approach, and we compare our approach to technical progress with theirs in Section 5. In this section, we extend the model to permit directed technical progress in machine, human and robot productivities which responds to the profit opportunities created by changing prices. In our setting, technical progress operates on the intensive margin in each sector, raising the productivity of different inputs and possibly generating spillovers for the productivity of that input in other sectors. It may well be that technical progress inherently favors one sort of input or sector over another. Whether and where such biases exist is an empirical matter. We maintain the neutrality of technological opportunities as an appropriate theoretical benchmark, and show that our long run distributional implications continue to be robust in such a setting even with endogenous technical progress. In summary, we argue that a falling labor share is a basic implication of a correctly specified baseline growth model that recognizes the fundamental asymmetry between the accumulation of physical and human capital. That implication is consistent with declining, constant or increasing absolute wages. The underlying logic applies in a fully competitive setting without technical progress, and survives in the presence of technical progress. It can be extended to incorporate monopolistic competition and rising markups, which represent possibly supplementary causes of declining labor shares. These latter effects may improve calibration or estimation. But the core logic lies deeper. 


\section{MODEL}

2.1. Production. There is a collection $I$ (initially finite) of final goods for consumption, indexed by $i$. In addition, there are three sectors for the production of robot services, education, and machine capital. The index $j$ serves as generic notation for any of this full collection of sectors. In any sector $j$, capital can have two roles. It is, first, a complementary input to labor. Think of such capital as "machine capital" $k_{j}$, used as input along with labor $\ell_{j}$ :

$$
y_{j}=f_{j}\left(k_{j}, \ell_{j}\right)
$$

where $f_{j}$ is increasing, smooth, strictly quasi-concave, and linearly homogeneous with $f_{j}(k, 0)=f_{j}(0, \ell)=0$, displaying unbounded steepness in each input at zero.

The second aspect of capital is its potential to displace human labor; think of such capital as "robot services." That is, view $\ell$ as labor input, representing tasks traditionally performed by humans $(h)$, but which can be automated by the use of robot services $(r)$. Specifically we presume that each unit of $h$ is worth one unit of "abstract labor" $\ell$ in sector $j$, while each unit of $r$ is equivalent to $\nu_{j}$ units of $\ell$. Without technical progress, $\nu_{j}$ is fixed once and for all in any given sector, and so $\ell_{j}=\nu_{j} r_{j}+h_{j}$. No sector can be freely automated, but nor can it fully protect humans: $\nu_{j} \in(0, \infty)$ for all $j$.

The assumption of linear substitutability of robots for humans simplifies the analysis, but it is not essential. Our results extend with no change to specifications with imperfect substitutability where one factor ceases to be used if its relative price is sufficiently high. Note, moreover, that humans may continue to work in automated sectors in our model (and generally will do so), provided they are willing to work at a wage which renders employers indifferent between them and robots. ${ }^{7}$

\footnotetext{
${ }^{7}$ This will happen, of course, if workers have specific skills which tie them to particular sectors, and are limited in their ability (at least in the short run) to move to other sectors. But it must be more generally true of equilibrium outcomes with finitely many or countably many sectors.
} 
We employ the convention throughout that final goods, robot services, and education are produced within the period, while machine capital is produced for the "next" period.

2.2. Prices. Within any date, machine capital services serve as numeraire: the rental price of $k$ will be set at 1 . The collection $\left(\boldsymbol{w}, w_{r}, w_{e}, w_{k}\right)$ is the wage system, where $\boldsymbol{w}=\left\{w_{i}\right\}$ are wages in final goods sectors. With free labor mobility, these wages would all be the same. The output prices are $\left(\mathbf{p}, p_{r}, p_{e}, p_{k}\right)$ for final goods, robot services, education, and capital goods. By constant returns to scale and the assumption of a pricetaking competitive economy, all prices will be pinned down by unit costs of production: ${ }^{8}$

$$
p_{j}=c_{j}\left(1, \lambda_{j}\right)
$$

where 1 is the return to machine capital, $\lambda_{j} \equiv \min \left\{w_{j}, \nu_{j}^{-1} p_{r}\right\}$ is the effective price of the labor input in sector $j$, and $c_{j}$ is the unit cost function, dual to the production function $f_{j}$. In a dynamic competitive equilibrium, these prices will generally vary with time.

2.3. Factor Demands and Automation. In each sector $j$, the demand for machine capital is given by the familiar marginal product criterion:

$$
p_{j} \frac{\partial f_{j}\left(k_{j}, \ell_{j}\right)}{\partial k_{j}}=1 .
$$

where we recall that the rental rate serves as numeraire. Likewise, labor demand (human or non-human) must satisfy

$$
p_{j} \frac{\partial f_{j}\left(k_{j}, \ell_{j}\right)}{\partial \ell_{j}}=\lambda_{j}
$$

If $w_{j}>\nu_{j}^{-1} p_{r}=\lambda_{j}$, sector $j$ is "fully automated," with $r_{j}=\ell_{j}$ and $h_{j}=0$. If $\lambda_{j}=w_{j}<\nu_{j}^{-1} p_{r}$, sector $j$ is "non-automated," with $h_{j}=\ell_{j}$ and $r_{j}=0$. Finally, for a "partially automated" (or simply "automated") sector $j$, we have $\lambda_{j}=w_{j}=\nu_{j}^{-1} p_{r}$, and so $h_{j}+\nu_{j} r_{j}=\ell_{j}$, with firms indifferent across all such combinations of $h_{j}$ and $r_{j}$.

\footnotetext{
${ }^{8}$ It is easy to check that our results extend to a context of monopolistic competition with CES preferences, as that generates a constant markup of price over cost in all sectors. Of course, profits would appear in that setting, so national income would be the sum of returns to capital, to workers and profits. Our distributional results would continue to apply to the share of wages in national income.
} 
2.4. Factor Endowments. At each date, the available machine capital and robot services move freely across sectors. (An extension of the model to accommodate sectorspecific machine capital and robots services is tedious but straightfoward.) Over time, the machine capital stock grows - or shrinks — depending on the rate of depreciation and the production function for capital. We assume that capital depreciates at rate $\delta \in[0,1]$ and take this rate to be independent of sector. ${ }^{9}$ Then at every date $t$,

$$
K(t+1)=(1-\delta) K(t)+y_{k}(t)
$$

Robot services fully depreciate within the period, but this involves no loss of generality. The view that robots are durable can easily be accommodated, by embedding robot services in machines. Those machines can be viewed as capital input to the robotproducing sectors, where they produce services again and again under the auspices of the robot production function $f_{r}$ (think of labor also being needed there for maintenance). Technically, all we do is move all the durability to the machine capital sector.

The stock of human labor is given in physical units. By constant returns to scale, it makes no difference if human labor grows exogenously; we will only need to re-normalize all variables by the rate of growth of labor. That said, we want to accommodate sectorspecific skill acquisition. We allow humans to differ in the sector-specific skills they are born with. So we take as given some initial allocation of the population across sectors. There could be a place-holding "null sector" where individuals without any acquired skill can be initially placed, or can "drop out" to at zero educational cost. At the beginning of every period, an individual can move from one sector to another. To move from sector $j$ to $j^{\prime}$ a person needs $e_{j j^{\prime}}$ units of education at the price $p_{e}$, the latter in turn endogenously determined by the unit cost of education. ${ }^{10}$ We allow for the possibility

\footnotetext{
${ }^{9}$ If depreciation rates are sector-dependent, then the net rate of return on capital is not defined by the equality of value of marginal products across sectors, and our normalization that the value of the marginal product of capital in every sector is set equal to 1 is no longer valid. Nothing substantive changes, however.

${ }^{10}$ If initial skills are not sector-specific, then everyone is in the null sector to start with, and education requirements can be written only as a function of the "destination sector" $j^{\prime}$. We can also accommodate "utility costs" of education that are nonlinear in wages, to mimic imperfect or missing capital markets.
} 
of depreciation of human capital; that is, it is possible for $e_{j j}$ to be strictly positive for some or all $j$. We place no restrictions on the amount of education needed to switch occupations, so the model captures both completely inflexible sector-specificity (no individuals can move at all) at one extreme to complete flexibility (where no education is needed to switch sectors) at the other extreme, and everything in between.

2.5. Preferences. A continuum of infinitely lived individuals, indexed by $m$, each has a continuous one-period utility function $u_{m}(\mathbf{x})$ defined on final goods consumption $\mathbf{x}$, a discount factor $\beta_{m} \in(0,1)$, and one unit of human labor. At the start of any date, an individual has financial wealth (representing her claims on capital) and some sectorspecific skill. She makes an education decision that moves her to a possibly new sector. Once within a sector, each individual supplies one unit of labor to that sector with no disutility, ${ }^{11}$ and is paid the sectoral wage. Then, given her wealth and income, she decides how much to spend today on different goods and how much to save, resulting in changes in financial wealth (the rate of return on which is endogenously determined).

For any expenditure $z$ on final goods and price vector $\mathbf{p}$, the demand vector for goods maximizes $u_{m}(\mathbf{x})$, subject to $\mathbf{p x} \leq z$. That generates a demand function $\mathbf{x}_{m}(\mathbf{p}, z)$. Denote by $v_{m}(z, \mathbf{p})$ the corresponding indirect utility function. We assume that $u_{m}$ satisfies whatever it needs to satisfy so that this indirect utility function is increasing, differentiable and strictly concave for every $\mathbf{p}$, with unbounded steepness at zero. Given some dated price-wage system for all goods, capital, and occupations, our agent maximizes

$$
\sum_{t=0}^{\infty} \beta_{m}^{t} v_{m}(z(t), \mathbf{p}(t)),
$$

subject to $F_{m}(0)$ given, by choosing occupation $j_{m}(t)$, education $e_{m}(t)$, current expenditure $z_{m}(t)$, and financial wealth $F_{m}(t+1)$ for every $t \geq 0$. Two feasibility conditions apply at every date. First,

$$
F_{m}(t)+w_{j_{m}(t)}(t)=z_{m}(t)+p_{e}(t) e_{m}(t)+\frac{F_{m}(t+1)}{\gamma(t)}
$$

\footnotetext{
${ }^{11}$ The assumption of zero disutility of working is inessential, since all that matters is the existence of an upper bound on the amount of labor that can be supplied by any individual.
} 
where $\gamma(t)$ is the endogenously determined "return factor" on financial wealth at date $t$ :

$$
\gamma(t)=\frac{1+(1-\delta) p_{k}(t+1)}{p_{k}(t)} .
$$

To understand (6), note that $F_{m}(t)$ corresponds to a claim on $K_{m}(t)$ units of machine capital net of depreciation, plus the rental on that capital before depreciation: $F_{m}(t)=$ $\left[1+(1-\delta) p_{k}(t)\right] K_{m}(t)$. In the same vein, one unit of machine capital bought at date $t$ at price $p_{k}(t)$ yields $\left[1+(1-\delta) p_{k}(t+1)\right]$ tomorrow. So the ratio of the latter term to the former must equal the return factor on financial wealth, which is (6).

The second feasibility condition describes the evolution of human capital. If our individual chooses a sequence of occupations $\left\{j_{m}(t)\right\}$, then for all $t$,

$$
e_{m}(t)=e_{j_{m}(t-1) j_{m}(t)}
$$

We can think of initial sectoral location " $j_{m}(-1)$ " as a real allocation or as some original null state from which she makes a move into the labor market.

By making education an intra-period choice we have suppressed issues of imperfect capital markets - the costs do not have to be paid upfront. We can easily introduce capital market imperfections with no changes to the results. Indeed, there may be a "least-cost education path" going from sector $j$ to sector $j^{\prime}$ which could entail "passing through" some low-paying additional sector(s) — "apprenticeships" — and such situations would effectively require upfront payments. We could also allow or disallow for borrowing on future income to sustain consumption smoothing. It really does not matter, but for concreteness we take $F_{m}(t) \geq B_{m}$ for all $t$, where $-B_{m} \geq 0$ represents a borrowing limit, and we impose $\liminf _{t} F_{m}(t) \geq 0$ to guarantee ultimate repayment of all debts.

We presume throughout that the above maximization problem is always well-defined. A quick way to ensure this is to assume that all utility functions are bounded. Of course there are well-known weaker conditions that can imposed, for instance, when utility functions have a well-defined asymptotic elasticity. 
2.6. Equilibrium. Given an initial allocation of individuals to sectors, $\left\{j_{m}(-1)\right\}$, and an initial allocation $\left\{k_{m}(0)\right\}$ of the capital stock $K(0)$ to all individuals, an equilibrium is a sequence of wages $\left\{\boldsymbol{w}(t), w_{r}(t), w_{e}(t), w_{k}(t)\right\}$, prices $\left\{\mathbf{p}(t), p_{r}(t), p_{e}(t), p_{k}(t)\right\}$ and quantities $\left\{F_{m}(t), z_{m}(t), e_{m}(t), j_{m}(t), k_{j}(t), r_{j}(t), h_{j}(t), y_{j}(t)\right\}$ for every person and every sector such that:

A. All individuals maximize lifetime utility as described in (4)-(7), with $F_{m}(0)=$ $p_{k}(0) k_{m}(0)$ for all $m$, and firms maximize per-period profits at every date.

B. The final goods markets clear: at every date, and for every final good $i$ :

$$
\int_{m} x_{i}\left(z_{m}(t), \mathbf{p}(t)\right) d m=y_{i}(t)
$$

C. The robot market clears; for each $t$ :

$$
y_{r}(t)=\sum_{i} r_{i}(t)+r_{r}(t)+r_{e}(t)+r_{k}(t)
$$

D. The human labor market clears; for each $t$ and each sector $j$, labor demand equals supply:

$$
h_{j}(t)=\operatorname{Measure}\left(m: j_{m}(t)=j\right)
$$

E. The capital market clears; for each $t, K(t)$ evolves as in (3), with:

$$
K(t)=\sum_{i} k_{i}(t)+k_{r}(t)+k_{e}(t)+k_{k}(t)
$$

and the available capital stock (net of depreciation) plus rental income on it is willingly absorbed by all individuals at each $t$ - refer to the discussion around (6):

$$
\left[1+(1-\delta) p_{k}(t)\right] K(t)=\int_{m} F_{m}(t) d m
$$

F. The education market clears; that is, for every $t$ :

$$
y_{e}(t)=\int_{m} e_{m}(t) d m, \text { where }\left\{e_{m}(t)\right\} \text { satisfies equation (7). }
$$


Per-capita national income (gross) is given by the expenditure on all final goods, plus investment in new capital goods and education: ${ }^{12}$

$$
Y(t)=\sum_{i} p_{i}(t) y_{i}(t)+p_{e}(t) y_{e}(t)+p_{k}(t) y_{k}(t)
$$

\section{Long Run Growth And Automation}

3.1. An Illustrative Example. Consider the following special case of our model: There is a single final good sector, indexed by 1 , with production function $y_{1}=k_{1}^{1 / 2} \ell_{1}^{1 / 2}$, a capital goods sector with production function $y_{k}=k_{k}^{1 / 2} \ell_{k}^{1 / 2}$, and a robot sector that has a CES production function with elasticity $1 / 2$ :

$$
y_{r}=\left[\frac{1}{2} k_{r}^{-1}+\frac{1}{2} \ell_{r}^{-1}\right]^{-1} .
$$

There is common robot productivity given by $\nu=\nu_{1}=\nu_{k}=\nu_{r}$, no education sector, and free mobility of labor across all three sectors with $\lambda$ the common corresponding price of effective labor. Then $\lambda$ is just the (common) wage $w$ if there is no automation, and it is $\nu^{-1} p_{r}$ if there is is (partial or full) automation. Let's record the unit cost functions. For the final good and machine sectors, these are $c_{1}(1, \lambda)=c_{k}(1, \lambda)=\sqrt{\lambda}$, and for the robot sector, it is $c_{r}(1, \lambda)=\frac{1}{2}[1+\sqrt{\lambda}]^{2}$. All individuals have the same one-period utility function $u(x)=\ln (x)$ along with discount factor $\beta \in(0,1)$.

To track equilibrium paths, notice that at any date, robot prices must be given by

$$
p_{r}(t)=c_{r}\left(1, \lambda_{r}(t)\right)=\frac{1}{2}[1+\sqrt{\lambda(t)}]^{2} .
$$

Case 1: $\nu \leq 1 / 2$. Then we claim that automation cannot occur. For if it did any date $t$, then it must be the case that $\lambda(t)=\nu^{-1} p_{r}(t)$. Substituting this into (15), we see that

$$
p_{r}(t)=\frac{1}{2}\left[1+\sqrt{\nu^{-1} p_{r}(t)}\right]^{2}>\frac{1}{2} \nu^{-1} p_{r}(t),
$$

which contradicts our premise that $\nu \leq 1 / 2$. So there is never any automation in any equilibrium. For $\beta$ large enough, an equilibrium involves unbounded accumulation of capital, an ever-growing wage rate, and a constant share of labor income $-50 \%$ in

\footnotetext{
${ }^{12}$ We could work with net national income by subtracting capital depreciation. Nothing changes.
} 
this example - in the long run. This last observation follows from the fact that the production functions for final goods and capital are Cobb-Douglas, and the fact that the robot sector shuts down in equilibrium, though prices for robots are well-defined and rise in tandem with human wages.

Case 2: $\nu>1 / 2$. Then, if the economy exhibits sustained growth of per-capita income — as it indeed will if individuals are patient enough — then all sectors that grow must be fully automated in the long run. For suppose this assertion is false. Then the percentage of human labor used in at least one of these growing sectors is bounded away from zero along a subsequence $\{\tau\}$ of dates. But because the total amount of human labor is bounded, so must be the overall labor input in that sector. Then sustained growth implies that sectoral machine capital grows without bound, so human wages climb to infinity. If there is no full automation, then $\lambda(\tau)=w(\tau)$, and using (15),

$$
p_{r}(\tau)=\frac{1}{2}[1+\sqrt{\lambda(\tau)}]^{2}=\frac{1}{2}[1+\sqrt{w(\tau)}]^{2},
$$

so that along the same subsequence,

$$
\frac{\nu^{-1} p_{r}(\tau)}{w(\tau)}=\frac{1}{2 \nu}\left[\frac{1}{\sqrt{w(\tau)}}+1\right]^{2} \rightarrow \frac{1}{2 \nu}<1 \text { as } t \rightarrow \infty
$$

but that would imply $\lambda(\tau)=\nu^{-1} p_{r}(\tau)<w(\tau)$ for large $\tau$, a contradiction.

We note five additional points. First, automation pins down robot prices relative to the rental rate of capital. This is akin to a "non-substitution theorem" and would be quite generally true even with heterogeneous robots and multidimensional machine capital. In this specific case, automation of the robot sector ensures that $p_{r}=p_{r}^{*}$, where - by (15) $-p_{r}^{*}$ solves the equation

$$
p_{r}^{*}=\frac{1}{2}\left[1+\sqrt{\nu^{-1} p_{r}^{*}}\right]^{2},
$$

and it can be checked that a solution to (16) is well-defined and unique, given $\nu>1 / 2{ }^{13}$

\footnotetext{
${ }^{13}$ Define a function $f(p)$ by $f(p)=(1 / 2 p)\left[1+\sqrt{\nu^{-1} p}\right]^{2}=(1 / 2)\left[\sqrt{p^{-1}}+\sqrt{\nu^{-1}}\right]^{2}$. Note that $f(p)$ is strictly decreasing and continuous, and that $f(p) \rightarrow \infty$ as $p \rightarrow 0$. Moreover, if $\nu>1 / 2, f(p)<1$ for $p$ large. It follows that there is a unique value $p_{r}^{*}$ such that $f\left(p_{r}^{*}\right)=1$.
} 
Second, the pinning-down of robot prices in (16) guarantees that with sustained growth, every sector that expands indefinitely must also become automated, no matter what its specific value of $\nu$ is. (In our example $\nu$ is the same for all sectors, but this is irrelevant.) For if this assertion were false for some growing sector, machine capital must grow without bound, and so therefore must human wages, showing that $p_{r}(t) / w(t)=p_{r}^{*} / w(t)$ must decline to zero, thereby precipitating automation, a contradiction.

Third, and relatedly, Case 2 is predicated on there being long-run growth to begin with. If per-capita income is bounded, then automation may not happen.

Fourth, full automation cannot be immediate, and indeed, it cannot occur at any finite time. The wage rate must equal $\nu^{-1} p_{r}^{*}$ in any automated sector and all humans must be hired at any date - otherwise they would contest the robots by undercutting them.

And finally, despite the full employment of labor, the share of labor in national income must decline to zero. By the previous point, that decline is "gradual" but with sustained growth, it is inexorable. Also, if we were to extend this example to have many sectors, with different values of $\nu$, the wage rate could progressively rise over time even as the share declines. Relative immiserization of the labor share is entirely consistent with absolute improvement of labor income.

However, the example is more obscure about the deeper conditions that separate Case 1 from Case 2. We now investigate this issue in more detail.

3.2. The Von-Neumann Singularity Condition. Consider the robot sector. Temporarily ignoring our choice of numeraire, fix the price of effective labor at $\lambda=1$ and take the capital rental rate - call it $\eta$ - to zero; that is, look at

$$
\lim _{\eta \rightarrow 0} c_{r}(\eta, 1)
$$

In words, imagine what happens to the unit cost of production as the capital input becomes nearly free. In the CES class with

$$
f_{r}(k, \ell)=\left[a k^{\frac{\sigma-1}{\sigma}}+(1-a) \ell^{\frac{\sigma-1}{\sigma}}\right]^{\frac{\sigma}{\sigma-1}}
$$


with $a \in(0,1)$ and the elasticity of substitution $\sigma \geq 0$, simple computation tells us that

$$
c_{r}(\eta, 1)=\left[a^{\sigma} \eta^{1-\sigma}+(1-a)^{\sigma}\right]^{1 /(1-\sigma)} .
$$

So our limit of interest equals zero when $\sigma \geq 1$, which includes the Cobb-Douglas case ("enough" substitution is available). But the limit is positive when $\sigma<1$. For instance, if the production function is "almost" Leontief, labor costs will enter unit cost no matter how cheap the machine input is. It turns out that this limit unit cost is related to the automation of the robot sector itself, a singularity envisaged by John von Neumann. ${ }^{14}$

PROPOSITION 1. Suppose that the following condition holds on the robot sector:

$$
\nu_{r}>\lim _{\eta \rightarrow 0} c_{r}(\eta, 1) .
$$

Then there is a unique positive solution $p_{r}^{*}$ to the equation

$$
p_{r}=c_{r}\left(1, \nu_{r}^{-1} p_{r}\right)
$$

and in any equilibrium, $p_{r}(t) \leq p_{r}^{*}$ for all $t$; i.e., the price of robots is bounded relative to the rental rate on capital. If at any date, the robot sector is automated, then $p_{r}=p_{r}^{*}$.

To understand the proposition, we begin by parsing (17). If it holds, then in any equilibrium - noting that $p_{r}$ equals unit cost — we would have $\nu_{r}>p_{r}$ for $\eta$ small, or $\nu_{r}^{-1} p_{r}<1$. That is, the effective price of robot services would fall below the labor price (fixed at 1) when $\eta$ is small, suggesting that robot production must be automated in such situations. That is why we call (17) a singularity condition, as it points towards automation of the robot sector, at least when capital is cheap relative to labor. In the CES case, observe that (17) must hold no matter how low the value of $\nu_{r}$ (or how inefficient robot services are relative to labor), provided the elasticity of substitution is 1 or more. When that elasticity falls below 1 , then (17) does restrict the value of $\nu_{r}$. Specifically,

$$
\text { Either } \sigma \geq 1 \text {, or } \sigma \in(0,1) \text { and } \nu_{r}>a_{\ell}^{\sigma / 1-\sigma} \text {. }
$$

\footnotetext{
${ }^{14}$ See von Neumann (1966), Theory of Self-Reproducing Automata: "The accelerating progress of technology, and changes in the mode of human life, give the appearance of approaching some essential singularity in the history of the race beyond which human affairs, as we know them, can not continue."
} 


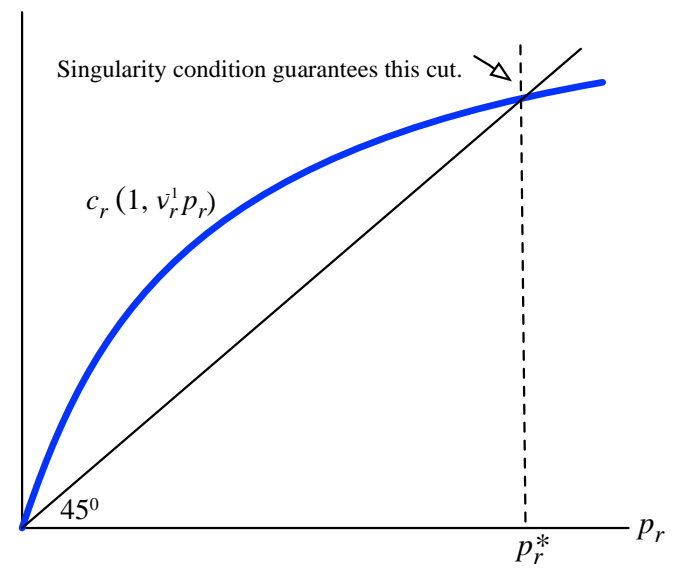

(A) Singularity Holds

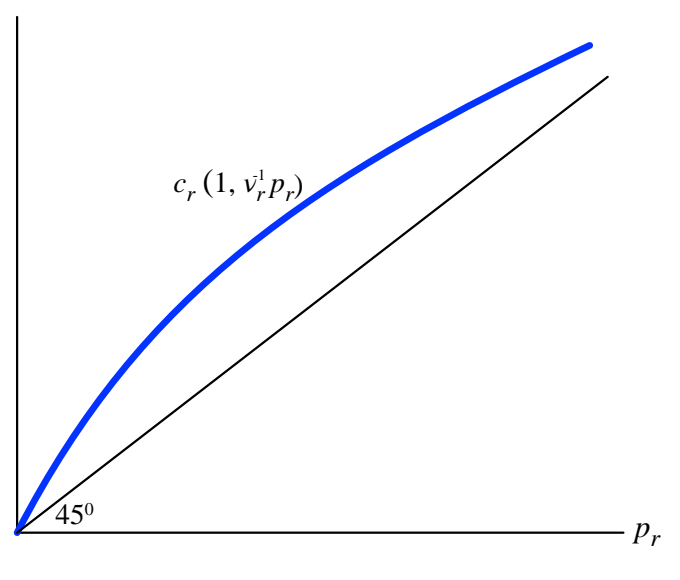

(B) Singularity Fails

Figure 1. The Singularity Condition (17) and the Bound on Robot Price

The result of Proposition 1 shows that under the singularity condition, the price of robots must join hands with the price of capital rather than the price of human labor, at least when human labor is relatively expensive. It is always true that

$$
p_{r}=c_{r}\left(1, \lambda_{r}\right) \leq c_{r}\left(1, \nu_{r}^{-1} p_{r}\right),
$$

the inequality holding because $\lambda_{j}=\min \left\{w_{r}, \nu_{r}^{-1} p_{r}\right\} \leq \nu_{r}^{-1} p_{r}$. Under the singularity condition, a little calculation shows that $c_{r}\left(1, \nu_{r}^{-1} p_{r}\right)$, viewed as a function of $p_{r}$, must ultimately dip below the $45^{0}$ line; see Panel A of Figure 1. So $p_{r}^{*}$ as described by (18) is well-defined and finite. (See Panel B to appreciate that $p_{r}^{*}$ will not be finite if the singularity condition fails.) Therefore (20) is equivalent to the assertion of the Proposition that $p_{r}(t) \leq p_{r}^{*}$ in any equilibrium and at every date. Moreover, if there is automation, then (20) holds with equality and $p_{r}(t)=p_{r}^{*}$. In this way, the singularity condition implies that the price of robot services must be tied to the price of capital rather than labor, even though both inputs can be used to produce those services.

\subsection{Automation and the Declining Labor Share Under Long Run Growth. We be-} gin with the case of finitely many final goods. But the dropping of finiteness will have conceptual (and not just technical) implications, as we shall explain in a later section. 
THEOREM 1. Suppose there are a finite number of consumer goods, and the robot sector satisfies the von Neumann singularity condition (17). Consider any equilibrium with long-run growth in per-capita income (i.e., $Y(t)$ grows to infinity as $t \rightarrow \infty$ ).

(i) There exists at least one sector $j$ and a subsequence along which $y_{j}(t)$ grows to infinity. Any such sector along any such subsequence must become automated by some finite date, and the share of sectoral labor performed by robots must converge to one.

(ii) Wages are bounded, and the share of human labor income must converge to zero.

Proof. Part (i). As $Y(t) \rightarrow \infty$, so must per capita consumption (a standard argument). Next, under the singularity condition, the price of every good $j$ is bounded above:

$$
p_{j}=c_{j}\left(1, \lambda_{j}\right) \leq c_{j}\left(1, \nu_{j}^{-1} p_{r}\right) \leq c_{j}\left(1, \nu_{j}^{-1} p_{r}^{*}\right) .
$$

So there is at least one sector $j$ and a subsequence along which $y_{j}(t) \rightarrow \infty$. We claim that any such $j$ must eventually be automated along any subsequence with unbounded output growth. If false, there is a further subsequence indexed by $\tau$ along which $j$ is non-automated, i.e., $w_{j}(\tau) \leq \nu_{j}^{-1} p_{r}(\tau)$ and $r_{j}(\tau)=0$ for all $\tau$. Now $y_{j}(\tau) \rightarrow \infty$, but $h_{j}(\tau)$ is bounded by the total labor endowment of the economy. Therefore, if $\hat{k}_{j}(\tau)$ and $\hat{h}_{j}(\tau)$ denote capital and human labor per unit of output at date $\tau$, then $\hat{k}_{j}(\tau)$ is bounded away from zero, while $\hat{h}_{j}(\tau) \rightarrow 0$ as $\tau \rightarrow \infty$. So invoking (2) for this sector, we see that

$$
p_{j}(\tau)=c_{j}\left(1, \lambda_{j}(\tau)\right)=c_{j}\left(1, w_{j}(\tau)\right)=\hat{k}_{j}(\tau)+w_{j}(\tau) \hat{h}_{j}(\tau)
$$

is bounded away from zero. Using the end-point condition on $f_{j}$, it follows that

$$
w_{j}(\tau)=p_{j}(\tau) \frac{\partial}{\partial h} f_{j}\left(k_{j}(\tau), h_{j}(\tau)\right) \rightarrow \infty \text { as } \tau \rightarrow \infty
$$

On the other hand, if sector $j$ is not automated along the subsequence $\{\tau\}$, we have $w_{j}(\tau) \leq \nu_{j}^{-1} p_{r}(\tau) \leq \nu_{j}^{-1} p_{r}^{*}$, which contradicts (23).

Next, we claim that the share of robot labor to total labor in sector $j$ must converge to one along this subsequence. Otherwise there exists some $\epsilon>0$ such that for all $\tau$,

$$
\epsilon \leq \Psi_{j}(\tau) \equiv \frac{h_{j}(\tau)}{\nu_{j} r_{j}(\tau)+h_{j}(\tau)},
$$


Then the total effective labor in that sector is bounded:

$$
\ell_{j}(\tau)=\nu_{j} r_{j}(\tau)+h_{j}(\tau) \leq \frac{h_{j}(\tau)}{\epsilon} \leq \frac{1}{\epsilon},
$$

where " 1 " is the total human labor endowment. Now we can write a version of (22):

$$
p_{j}(\tau)=c_{j}\left(1, \lambda_{j}(\tau)\right)=\hat{k}_{j}(\tau)+\lambda_{j}(\tau) \hat{\ell}_{j}(\tau)
$$

and then observe - analogous to the way we derived (23) - that

$$
\lambda_{j}(\tau)=p_{j}(\tau) \frac{\partial}{\partial \ell} f_{j}\left(k_{j}(\tau), \ell_{j}(\tau)\right) \rightarrow \infty \text { as } \tau \rightarrow \infty
$$

But (25) contradicts $\lambda_{j}(\tau)=\nu_{j}^{-1} p_{r}(\tau)$, because Proposition 1 tells us that $p_{r}(\tau)$ is bounded above by $p_{r}^{*}<\infty$. This concludes the proof of (i).

Part (ii). We drop the index $t$ for notational ease. Recall (14) to write out income:

$$
Y=\sum_{i} p_{i} y_{i}+p_{e} y_{e}+p_{k} y_{k}
$$

This can be expressed as the sum of (machine) capital and human income. Formally,

$$
\begin{aligned}
Y & =\sum_{i} p_{i} y_{i}+p_{e} y_{e}+p_{k} y_{k}=\sum_{j \neq r}\left[k_{j}+p_{r} r_{j}+w_{j} h_{j}\right] \\
& =\sum_{j \neq r}\left[k_{j}+w_{j} h_{j}\right]+p_{r}\left[y_{r}-r_{r}\right]=\sum_{j \neq r}\left[k_{j}+w_{j} h_{j}\right]+\left[k_{r}+w_{r} h_{r}\right] \\
& =\sum_{j}\left[k_{j}+w_{j} h_{j}\right]=K+\sum_{j} w_{j} h_{j} .
\end{aligned}
$$

Defining $\underline{\nu} \equiv \min _{j} \nu_{j}>0$, Proposition 1 implies that for every sector $j$ with $h_{j}>0$,

$$
w_{j} \leq \nu_{j}^{-1} p_{r} \leq \nu_{j}^{-1} p_{r}^{*} \leq \underline{\nu}^{-1} p_{r}^{*}
$$

So $\sum_{j} w_{j} h_{j}$ is bounded, and the result follows from (27) and $Y \rightarrow \infty$.

The singularity condition generates a upper bound (in capital rental units) on the unit cost of producing robots. That in turn creates an upper bound to human wages in every sector, owing to the automation threat. So wage income is bounded, implying that the share of humans in national income must go to zero as income grows unboundedly in the long run (Part (i)). Part (i) states that in every sector that is "consequential" in the long run must 
eventually become automated, with human labor asymptotically insignificant relative to robots. Otherwise, the capital-labor ratio in that sector must grow to infinity, resulting in ever-growing human wages - an outcome prevented by the threat of automation.

By the same argument, the share of human labor in value added within any consequential sector must also converge to zero. A standard CES model without "micro-level" automation will not generate this result, unless the elasticity of substitution between capital and labor exceeds one (which runs counter to the empirical evidence based on the CES specification). Our theory therefore predicts a falling labor share, without any technical progress or assumptions on the elasticity of substitution between machine capital and labor within any sector (with the exception of the singularity condition in the robot sector). Capital does substitute for labor, but through an automation process which is not at all captured in a reduced-form CES specification. So Theorem 1 can be stated in substantial generality, making no assumptions about the structure of preferences, labor specificity, or the determinants of human capital investments (education costs, or household borrowing constraints), barring those required to assure ongoing growth.

The asymmetry between human and physical capital is fundamental to our argument. The notion that human capital in the same activity or sector can be indefinitely multiplied is one that we explicitly exclude. Therefore per-capita growth must imply progressive capital deepening. With the singularity condition in hand, the production cost of robots can be divorced from human wages altogether, thereby bounding those wages.

That said, our analysis is restrictive in the following sense: we've limited the scope for humans to respond to automation in sectors they have been traditionally been working in, by investing in skills needed to enter sectors that are yet to be automated. If every sector eventually gets automated at some date, there are no sectors left for humans to escape to. That is why we now drop the assumption of finitely many sectors.

3.4. An Unbounded Number of Sectors. We now consider an infinite number of final goods sectors. That dispenses with the presumption of a uniform upper limit to the effectiveness of humans relative to robots across all sectors, i.e., a limit to the extent 
to which humans are protected from automation anywhere in the economy. We allow humans to "escape towards" low-automation sectors by accumulating human capital in a directed way. The wages in such sectors might be rising progressively, without bound, and in this way humans can retain a positive fraction of national income in the long run.

But the intersectoral migration of humans requires market acquiescence on the demand side. The ability of low-automation sectors to absorb humans depends on the composition of demand as the economy grows. We show that the extent of migration is inadequate to prevent the slide in human labor share, if household preferences are homothetic. In fact, as explained below, this inadequacy persists if homotheticity were relaxed to apply only to preferences of "arbitrarily affluent" households.

That said, the conclusion regarding bounded human wages in Theorem 1 no longer applies. Under conditions to be described, humans enjoy unboundedly large wages in the long run, even as the share of those wages in national income declines to zero.

Turn now to the details. Without loss of generality arrange the goods so that $\nu_{i} \geq$ $\nu_{i+1}$ for all $i$. We impose no assumption on $\lim _{i} \nu_{i}$, allowing this limit to be 0 . All other assumptions on the production side of the economy remain unchanged. As for preferences, each one-period utility indicator $u_{m}$ is now defined on infinite-dimensional vectors of final goods. For technical reasons, we suppose that there are only finitely many distinct utility functions and discount factors. We assume that for every $m, u_{m}$ is homothetic, and that a demand function $\mathbf{x}_{m}(\mathbf{p}, z)$ is well-defined for every strictly positive price vector $\mathbf{p}$. By homotheticity, that demand function can be factorized as:

$$
\mathbf{x}_{m}(\mathbf{p}, z)=\mathbf{d}_{m}(\mathbf{p}) z
$$

for some function $\mathbf{d}_{m}$. We place mild restrictions on this demand function:

[Well-Behaved Preferences] If a bounded sequence of strictly positive price vectors $\left\{\mathbf{p}^{n}\right\}$ converges to $\mathbf{p} \gg 0$, then for each $m, \mathbf{d}_{m}\left(\mathbf{p}^{n}\right) \rightarrow d_{m}(\mathbf{p})$. On the other hand, if $p_{i}^{n} \rightarrow 0$ for some set $I$ of sectors, then $\liminf { }_{n} d_{i m}\left(\mathbf{p}^{n}\right)>0$ for at least one index $i \in I$. 
Dixit-Stiglitz preference aggregators with elasticity of substitution no less than 1 satisfy this condition. So do the additional restrictions on demand invoked (only) in the last part of the next Theorem, the proof of which is relegated to the Supplementary Appendix.

THEOREM 2. Consider an infinite number of consumer goods. Suppose that the singularity condition (17) holds, and that preferences are homothetic and well-behaved. Consider any equilibrium with long-run growth in per-capita income, as defined in Theorem 1. Then:

(i) Part (i) of Theorem 1 continues to be true.

(ii) The share of human labor in national income converges to zero as $t \rightarrow \infty$.

(iii) If, moreover, the following additional assumptions hold, the wage earned by every human goes to infinity as $t \rightarrow \infty$ :

[Positive Demand] For each price $\mathbf{p} \gg 0, d_{m i}(\mathbf{p})>0$ for infinitely many goods $i$.

[Protection] There is a sequence of sectors progressively friendly to humans: $\nu_{i} \rightarrow 0$.

[Bounded Education Costs] If $E_{j j^{\prime}}$ denotes education costs along the least-cost path from $j$ to $j^{\prime},{ }^{15}$ then $\sup _{j, j^{\prime}, j^{\prime \prime}}\left|E_{j j^{\prime}}-E_{j j^{\prime \prime}}\right|<\infty$.

The model now allows for sectors in which the comparative effectiveness of robots vis$a$-vis humans is arbitrarily low. At the same time, every consequential sector is under pressure to eventually become automated. If both these statements are true, it must be that at any date, no matter how distant, there will exist sectors that are yet to be automated. And yet as time goes by, more sectors become automated, and in these the share of human wages will shrink to zero. Since the human share is positive in yet-tobe-automated sectors, the aggregate share of human wages in national income can be positive in the long run only if expenditure shares on these sectors are bounded away from zero. This is a race between two limits, but the "positive share" camp cannot win

\footnotetext{
${ }^{15}$ As discussed above, there may be a "least-cost education path" which passes through some lowpaying sector(s). $E_{j j^{\prime}}$ is obtained by simply adding educational requirements for every step of this path.
} 
as long as preferences are homothetic and well-behaved. Their share must shrink to zero. Intuitively, in the long run, market demand cannot generate sufficient entry into the ever-shrinking set of "niche" sectors where humans are yet to be displaced.

At the same time, part (iii) of the theorem permits the absolute return to human labor to grow without bound, at the same time that their return relative to that of capital converges to zero. Part (iii) is not applicable generally — it rests on the assumption that education costs are bounded across all pairs of occupations - but it is nevertheless of interest to see that absolute doom can be warded off even as relative doom is inevitable.

Hometheticity is sufficient for Theorem 2 but not necessary. For instance, a perusal of its proof will reveal that it would survive under "asymptotic homotheticity;" i.e., if (28) were assumed to be approximately true only for large values of income. It would also remain true even in the absence of any homotheticity restriction on preferences, as long as with rising income, those preferences favor subsets of goods with the ratio of robot to human productivity bounded away from zero. There appears to be only one way to break the stranglehold imposed by the theorem: if preferences are non-homothetic and move progressively in favor of goods where humans have the largest productivity advantage over robots: examples of this can be constructed. ${ }^{16}$

\section{What Guarantees Long Run Growth?}

Theorems 1 and 2 are predicated on the assumption of long-run growth, which isn't a testable restriction on the primitives of the model. A theorem of the following kind might be preferable: "There exists a threshold for the discount factor (large enough) such that if some discount factors in the economy exceed this threshold, then the economy exhibits long-run growth." We believe such a theorem to be true, but under the current

\footnotetext{
${ }^{16}$ Comin, Danieli and Mestieri (2019) describe non-homotheticities in demand which raise the share of services and lower that of agriculture, and are associated with rising wage polarization. They do not investigate the implications for the decline in overall labor income share. Karabarbounis and Neiman (2014) argue that this decline is mainly intrasectoral, and not driven by changing intersectoral composition.
} 
generality of our model we do not know (yet) how to prove it. We provide two special cases where such a result can be established:

(i) Self-Reproducing Machines: The capital goods producing sector only uses machines to produce capital:

$$
f_{k}(k, \ell)=a k,
$$

for some $a>0$.

(ii) Single Consumer Good: Re-interpret the model as one where each final good produced is actually an intermediate good (while machines, robots and education are "basic" goods), and these intermediate goods combine to produce a single consumer good via a concave CRS production function $Y\left(\left\{f_{j}\left(k_{j}, \nu_{j} r_{j}+h_{j}\right)\right\}\right)$.

Consider (i) first. It is obvious that along any equilibrium path, the price of capital is just the rental rate times $1 / a$; so given our normalization, $p_{k}(t)=1 / a$ for all $t$. Therefore, invoking (6), the rate of return on financial capital is given by

$$
\gamma(t)=\gamma=\frac{1+(1-\delta)(1 / a)}{1 / a}=a+(1-\delta) .
$$

for all dates $t$. In the case of a single consumer good, a similar result can be established: ${ }^{17}$

ObSERVATIOn 1. Suppose (ii) applies, and (17) holds. Then the marginal product of machine capital is bounded below by $a \equiv \frac{1}{c_{y}\left(\left\{c_{j}\left(1, \nu_{j}^{-1} p_{r}^{*}\right\}\right)\right.}$.

Proof. Use the single consumer good as numeraire. Consider any date $t$ competitive equilibrium, in which the marginal product of capital must be equal in all sectors: $R \equiv$ $F_{k}=f_{j k}$ for all $j$. Then $p_{r} \leq c_{r}\left(R, \nu_{r}^{-1} p_{r}\right) \leq R p_{r}^{*}<\infty$ by (17). Hence

$$
p_{j} \leq c_{j}\left(R, \nu_{j}^{-1} p_{r}\right) \leq c_{j}\left(R, \nu_{j}^{-1} R p_{r}^{*}\right)=R c_{j}\left(1, \nu_{j}^{-1} p_{r}^{*}\right)
$$

If $c_{y}$ denotes the unit cost function of $Y$ :

$$
1=c_{y}\left(\left\{p_{j}\right\}\right) \leq R c_{y}\left(\left\{c_{j}\left(1, \nu_{j}^{-1} p_{r}^{*}\right\}\right)\right.
$$

\footnotetext{
${ }^{17}$ We are grateful to Pascual Restrepo for pointing out this result.
} 
which implies

$$
R \geq a \equiv \frac{1}{c_{y}\left(\left\{c_{j}\left(1, \nu_{j}^{-1} p_{r}^{*}\right\}\right)\right.}>0
$$

Hence, in both cases, the economy is an $a K$ economy, in which long run growth in per capita income must occur if a positive measure of individuals exhibit sufficient time preference relative to $a$.

THEOREM 3. Assume (17), that either Case (i) or (ii) applies, and that for a positive measure of individuals,

$$
\beta_{m}[a+(1-\delta)]>1
$$

where a is either given in Case (i) or by Observation 1 in Case (ii). Then the economy exhibits long-run growth, and Theorems 1 and 2 must apply.

\section{TECHNiCAl PRogress}

We extend the theory to incorporate directed technical progress. "Directedness" means that technical progress is geared to input scarcity. The key assumption we make is that the opportunities for such progress are symmetric over all inputs, and across all sectors. This is not to deny the possibility that the nature of science and technology might generate biases in certain directions. But studying the effect of such exogenous biases would not need a theory. If they were to favor unbridled automation, our results would be a foregone conclusion. If they favored the augmentation of human quality over robots, that would raise the share of humans in national income instead.

The two possibilities combined point to a long run "balanced-growth" view of technical progress, a view developed by Acemoglu and Restrepo (2018, 2019), with antecedents in a literature that includes Hicks (1932), Salter (1966), Galor and Maov (2000), and Acemoglu (1998, 2002), among many others. Acemoglu and Restrepo (2018) generate balanced growth by assuming that newly developed tasks lie in the human domain, enjoying temporary protection from the robot invasion. But the robots are also hard 
at work, automating existing tasks and perennially chasing the moving human frontier created by new tasks. Balance is achieved by equilibrium across these two forces. This is a potentially fruitful approach, but one that is - perhaps unavoidably - laden with questions. Why can't new tasks that favor robots also appear on the frontier of technical progress? Or (the flip side): why cannot humans recover their edge in old tasks? What if there is technical progress in machines?

In this section, we take a more neutral view. We consider a fixed number of sectors and tasks, and technical progress occurs on the intensive rather than extensive margin. There is no a priori restriction on sectors in which humans and robots can be active. In contrast, Acemoglu and Restrepo study the extensive margin, where the task space is extended in the asymmetric way already described. In particular, within each sector/occupation, we allow for technical progress in (non-robot) machine capital, on par with the possibility of technical progress in human labor, and in robot capital. As we will see, technical progress in non-robot capital will play an important role in our analysis. ${ }^{18}$

The sole asymmetry we retain — one we've already developed - is the difference between the scaling-up of physical and human capital. It will turn out that this asymmetry is augmented in the presence of symmetric (though directed) technical progress. To us, this is the natural theoretical benchmark. If there are stronger opportunities for technical progress that heighten the productivity of machine capital or robots relative to humans, our results will a fortiori be reinforced. And in the opposite case they will be moderated.

We presume that productivity growth in any factor in any given sector spills over to the same factor in other sectors. ${ }^{19}$ There is empirical evidence of such spillovers (see, e.g., Bernstein and Nadiri 1988 and Johnson 2018). Such spillovers will ensure that the rate of productivity growth of any factor cannot diverge across sectors in the long run. ${ }^{20}$

\footnotetext{
${ }^{18}$ Acemoglu and Restrepo abstract from non-robot machine capital in their model.

${ }^{19}$ Acemoglu and Restrepo (2019) assume a single sector, avoiding the complications from multiple sectors and inter-sectoral spillovers. But we do not consider this item to be a fundamental source of difference in the results.

${ }^{20}$ In the complete absence of spillovers, Theorem 4 may not hold; details available on request.
} 
5.1. Framework. We consider the baseline model with finitely many sectors. To allow for changes in the productivity of every input, we attach coefficients to physical capital and human labor in addition to the already-noted robot productivity $\nu$. So:

$$
y_{j}=f_{j}\left(\theta_{j} k_{j}, \mu_{j} h_{j}+\nu_{j} r_{j}\right)
$$

where the same assumptions are made on $f_{j}$ as before, and $\left(\theta_{j}, \mu_{j}, \nu_{j}\right) \gg 0$ are productivities that can be changed by deliberate technical progress.

We assume that the singularity condition holds on the robot-sector cost function, evaluated at the starting robot productivity $\nu_{r}(0)$ at date 0 :

$$
\nu_{r}(0)>\lim _{\eta \rightarrow 0} c_{r}(\eta, 1)
$$

The later robot productivities will all be endogenous and so we impose no restrictions involving these, but it is easy to see that (31) could be further weakened. All our results hold for any competitive equilibrium for which (31) holds at some date $t$ along the equilibrium path.

5.2. Endogenous Technical Progress. We presume that each factor-sector pair is serviced by a short-lived, sector-specific inventor whose activities and returns are external to the economy in question. ${ }^{21}$ She can generate an increase in the sectoral productivity of that factor. In particular, assume that the productivity $\pi_{j}(t)$ of a typical factor in sector $j$ at $t$ can be increased at some rate $\rho_{j}(t)$ through R\&D investment. A fixed proportion $\gamma>0$ of this growth spills over to the same factor in other sectors, subject to a maximum

\footnotetext{
${ }^{21}$ We can fully integrate the inventor into the economy by providing her with a production technology that again depends on machine capital and human/robot labor. We avoid that recursive extension here. However, one difference that will arise is that unlike all other sectors, 'firms' in the R\&D sector will not be perfectly competitive, and will earn profits which will typically constitute a positive fraction of national income. The extent to which humans can be replaced by robots in the R\&D sector then is an additional determinant of the share of humans in national income. This will be driven by the logic of cost minimization in the production of $R \& D$, in a manner similar to that in other sectors. Hence it is possible to extend the model in this direction as well, without any qualitative change.
} 
rate $\bar{\rho}$ of productivity growth in any sector. So for any sector $j$ :

$$
\pi_{j}(t+1)-\pi_{j}(t)=\max \left\{\rho_{j}(t) \pi_{j}(t)+\gamma \sum_{j^{\prime} \neq j} \rho_{j^{\prime}}(t) \pi_{j^{\prime}}(t), \quad \bar{\rho} \pi_{j}(t)\right\} .
$$

The associated $\mathrm{R} \& \mathrm{D}$ cost of the inventor is $\kappa(\rho)$, where $\kappa^{\prime}(0)=0, \kappa^{\prime}(\rho)>0$ and $\kappa^{\prime \prime}(\rho)>0$ for all $\rho$. View R\&D investment as a game played across sectors and factors by inventors. Then for any $i, \rho_{j}(t)$ can be positive only if the first term on the right-hand side of (32) binds. So our inventor is either inactive, or fully owns (and so can license) the proprietary advance $\rho_{j}(t) \pi_{j}(t)$ to firms operating in sector $j$ in period $t+1$. The license fee is levied per (natural) unit of the factor employed by the firm at $t+1$. On the other hand, the spillovers are in the public domain, utilized freely by all firms.

Each inventor takes prices as given, as in competitive innovation models of Grossman and Hart (1979) and Makowski (1980). The maximum license fee $L_{j}(t+1)$ that can be charged by a date- $t$ inventor is

$$
L_{j}(t+1)=q_{j}(t+1) \rho_{j}(t)
$$

where $q_{j}(t)$ is the relevant factor price at $t$. This is because the one efficiency unit of the factor costs $\frac{q_{j}(t+1)}{\pi_{j}(t)}$ for someone without access to the technical advance, while it costs $\frac{q_{j}(t+1)}{\left(1+\rho_{j}(t)\right) \pi_{j}(t)}$ for someone who has access to it. The difference in unit cost is precisely $\frac{q_{j}(t+1) \rho_{j}(t)}{\pi_{j}(t)\left(1+\rho_{j}(t)\right)}$, so this can be sucked out as a license fee per efficiency unit. Multiplying by the number of efficiency units $\pi_{j}(t)\left(1+\rho_{j}(t)\right)$ made possible by the advance, we obtain expression (33). Intuitively, the "effective factor price" for licensees must rise by exactly the same proportion as the proprietary productivity advance.

It follows that if $x_{j}(t)$ is the scale of employment of that factor in sector $j$ at date $t$, the total return earned by the inventor equals $L_{j}(t+1) x_{j}(t+1)=\rho_{j}(t) E_{j}(t+1)$, where $E_{j}(t+1) \equiv q_{j}(t+1) x_{j}(t+1)$ is the total bill for that factor in sector $j$. Therefore, given the R\&D choices $\left\{\rho_{j}^{\prime}(t)\right\}_{j^{\prime} \neq j}$ by inventors in other sectors, and given that our inventor is specific to the sector at hand, she will invest until $\kappa^{\prime}\left(\rho_{j}(t)\right)=$ $E_{j}(t+1)$ - provided $\kappa^{\prime-1}\left(E_{j}(t+1)\right) \pi_{j}(t)+\gamma \sum_{j^{\prime} \neq j} \rho_{j^{\prime}}(t) \pi_{j^{\prime}}(t)<\bar{\rho}$ - and $\max \{0, \bar{\rho}-$ 
$\left.\gamma \frac{1}{\pi_{j}(t)} \sum_{j^{\prime} \neq i} \rho_{j^{\prime}}(t) \pi_{j^{\prime}}(t)\right\}$ otherwise. So the Nash equilibrium rate of productivity increase must satisfy:

$$
\frac{\pi_{j}(t+1)-\pi_{j}(t)}{\pi_{j}(t)}=\max \left\{\kappa^{\prime-1}\left(E_{j}(t+1)\right)+\gamma \frac{1}{\pi_{j}(t)} \sum_{j^{\prime} \neq j} \rho_{j^{\prime}}(t) \pi_{j^{\prime}}(t), \quad \bar{\rho}\right\}
$$

5.3. Equilibrium. With this setup, an equilibrium looks just like the competitive equilibrium in Section 2.6. That is because licensees give up all their surplus to the inventor, so that they effectively use the old technology until the new innovations enter the public domain. With the rental rate on capital once again chosen as numeraire, an equilibrium is a sequence of wages $\left\{\boldsymbol{w}(t), w_{r}(t), w_{e}(t), w_{k}(t)\right\}$, prices $\left\{\mathbf{p}(t), p_{r}(t), p_{e}(t), p_{k}(t)\right\}$ and associated quantities $\left\{F_{m}(t), z_{m}(t), e_{m}(t), j_{m}(t), k_{j}(t), r_{j}(t), h_{j}(t), y_{j}(t)\right\}$ for every person and every sector, along with productivity coefficients $\left\{\theta_{j}(t), \mu_{j}(t), \nu_{j}(t)\right\}$ for every input, sector, and date, such that:

(a) Given the sequence of productivities, the remaining sequence of outcomes constitutes a competitive equilibrium; and

(b) At every date, and for every sector and factor, given the equilibrium prices and quantities, productivity changes are the outcome of a Nash equilibrium as described earlier in this section.

\subsection{Automation and the Vanishing Labor Share with Technical Progress. To state} the main result of this section, we invoke two additional conditions. First, we assume that consumer expenditure shares on each final good are bounded away from zero:

[E] For any individual type $m$ and $\operatorname{good} i, \inf _{(\mathbf{p}, z) \gg 0} p_{i} x_{m i}(\mathbf{p}, z) / z>0$.

As there are a finite number of goods, this is fairly innocuous. Next, we make an additional assumption on the production technology:

$[\mathrm{F}]$ There is some final good $i$ for which $\lim _{\zeta \rightarrow 0} c_{i}(1, \zeta)>0$. 
It is easy to verify that Condition F holds as long as there is at least one final good sector with constant elasticity of substitution strictly smaller than $1 .^{22}$

THEOREM 4. Assume the singularity condition (31), and Conditions $E$ and F. Then in any equilibrium which exhibits unbounded accumulation of machine capital, the wage earned by human labor in every sector is bounded, and the income share of human labor in the economy as a whole must converge to zero as $t \rightarrow \infty$.

Theorem 4 resurrects the dismal prediction on human labor shares. It continues to highlight the effects of our maintained asymmetry across the accumulation of human and physical (or financial) endowments. The theorem makes, again, an assumption on growth. But this time the assumption is stronger, asking that capital be accumulated in equilibrium. It is possible to provide sufficient conditions for this, along the lines of Theorem 3. Now, technical progress induces a downward drift on prices (relative to incomes), which is an "automatic" — albeit endogenous - source of real income growth. For machine capital to be willingly accumulated despite this drift, the degree of patience must clear a higher threshold (which depends on the maximal rate $\bar{\rho}$ of technical progress), so that per-capita growth at this maximal rate is not enough to deter households from saving and investing at a positive rate.

We also note that we have not modeled the use of inputs in the R\&D sector, so the theorem as stated does not include human wages in R\&D. We could model this, of course,

\footnotetext{
${ }^{22} \mathrm{We}$ believe that both conditions $\mathrm{E}$ and $\mathrm{F}$ are technical. Condition $\mathrm{E}$ is possibly needed for the result, but is mild. As for Condition F, we don't know if it can be dropped free of charge. We do know that it can be replaced by other conditions. For instance, for any sector $j$, define the intensive-form function $g_{j}(e) \equiv f_{j}(e, 1)$. Then the following condition substitutes for $\mathrm{F}:\left[\mathrm{F}^{\prime}\right]$ There is some sector $j$ such that the infimum elasticity of the intensive form is positive:

$$
\inf _{e>0} \frac{g_{j}^{\prime}(e) e}{g_{j}(e)}>0 .
$$

Conditions $\mathrm{F}$ and $\mathrm{F}^{\prime}$ are not nested. A CES production function with elasticity of substitution smaller than 1 satisfies $\mathrm{F}$ but not $\mathrm{F}^{\prime}$. A Cobb-Douglas production function satisfies $\mathrm{F}^{\prime}$ but not $\mathrm{F}$.
} 
by including $\mathrm{R} \& \mathrm{D}$ as one of the sectors indexed by $j$, and by allowing for automation in that sector as well. We refrain from that obvious extension here.

We outline the main steps to prove Theorem 4, relegating technical details to the Supplementary Appendix.

LEMMA 1. (a) For each factor and sector $j$, there is $M<\infty$ such that factor productivity in $j$ grows at rate $\bar{\rho}$ if the factor bill $q_{j} x_{j}$ for that factor exceeds $M$.

(b) If the spillover rate $\gamma$ is positive, the relative productivity $\pi_{j}(t) / \pi_{j^{\prime}}(t)$ of any factor between any pair of sectors $j$ and $j^{\prime}$ is bounded.

Part (a) is straightforward, following from (34). If the factor bill $\left.E_{j}(t+1)\right)$ is large enough, the right-hand-side of (34) will equal the maximal rate $\bar{\rho}$ of technical progress. This reflects the force of the intensive margin in motivating technical progress in sector $j$. Part (b) ensures that the benefits of technical progress in any sector spills over to other sectors, thereby preventing inter-sectoral divergence of factor productivity.

Lemma 2. Assume (31). For any $j$, there is $B_{j}<\infty$ such that in any equilibrium,

$$
\theta_{j}(t) \frac{p_{r}(t)}{\nu_{r}(t)} \leq B_{j} \text { for all } t
$$

The singularity condition (31) places a bound on robot prices $p_{r}(t) / \nu_{r}(t)$ in efficiency units, relative to the capital rental rate $1 / \theta_{r}(t)$ in the robot sector. Spillovers across sectors then imply that the same is true in every other sector in the long run, as a consequence of part (b) of Lemma 1. That gives us the bound in (35).

Next, the unbounded accumulation of aggregate capital in natural units is likely to be spread across sectors, so there will exist sectors in which the use of capital in natural units will grow unboundedly. This can be verified to be true under Conditions $\mathrm{E}$ and F:

LEMMA 3. If $E$ and $F$ hold, in any equilibrium with $K(t) \rightarrow \infty$, it must be the case that $k_{i}(t) \rightarrow \infty$ for some sector $i$. 
The statement of the lemma is deceptively simple. Condition E ensures that household expenditure shares of different sectors cannot fluctuate "too much" across dates, so the expenditure on each good must grow unboundedly in the long run. So the value of output in any final good sector cannot fluctuate excessively, and must also grow. Condition F implies a bounded ratio of output value to machine capital for at least some sectors, and in these, the amount of machine capital allocated must grow without bound. The rate of technical progress in machines must eventually be maximal in these sector, and it spills over to every other sector. In brief, the rate of technical progress in machine capital cannot fall behind the rate of technical progress in human labor in the long run.

These three steps are combined as follows. The asymmetric growth in endowments in natural units between machine capital and human labor generates a bias (at least weakly) in technical progress in favor of capital. That compounds the distributional shift in favor of physical capital, and so our preceding results concerning the long run income share of human labor continue to hold in the presence of directed technical progress. Specifically, in any sector $j$ that employs human labor at any date $t$, humans must be cost-effective relative to robots:

$$
\frac{w_{j}(t)}{\mu_{j}(t)} \leq \frac{p_{r}(t)}{\nu_{j}(t)} \leq \frac{B_{j}}{\theta_{j}(t) \nu_{j}(t)},
$$

where the second inequality follows from Lemma 2. This implies that the wage earned by humans is bounded in every sector in which humans are employed, since (36) implies that

$$
w_{j}(t) \leq \frac{\mu_{j}(t)}{\theta_{j}(t)} \frac{B_{j}}{\nu_{j}(t)} .
$$

Now, $\frac{\mu_{j}(t)}{\theta_{j}(t)}$ is bounded, because machine capital productivity grows at least as fast as human productivity in every sector in the long run - an implication of Lemma 3 while $\nu_{j}(t)$ is non-decreasing in $t$. So human wages are bounded, just as they were in the absence of technical progress, implying that the share of human labor income in national income must converge to 0 in the long run, as $K_{t} \rightarrow \infty$.

Once again, these arguments rest on the underlying asymmetry between the growth of physical capital and human labor in natural units. Unbounded capital accumulation 
relative to human labor implies a corresponding asymmetry in factor bills, and thereby in technical progress on the intensive margin. That induces a parallel asymmetry in rates of technical progress, precisely unveiled by our insistence that the opportunities for technical progress are symmetric.

\section{CONCluding Remarks}

We study long-term automation and decline in the labor share, driven by capital accumulation rather than biased technical progress or rising markups. Our argument relies on a fundamental asymmetry across physical and human capital in modern economies. While physical capital can be scaled up for the same activity and accumulates in natural units, human capital accumulates principally via education and training that alters choice into higher-skilled occupations, but — from the vantage point of a household or individual - cannot scale up the quantity of labor for a given occupation to an unlimited degree. Under a singularity condition on the technology of the robot-producing sector, we show that the share of capital in national income approaches $100 \%$. We argue that this lack of balancedness should be a primitive property of a benchmark growth model.

The singularity condition is central to our findings. So the condition itself merits greater scrutiny. There is greater recognition that the "production of robots by means of robots" is not merely a hypothetical possibility. The Technology section of the New York Times (November 5, 2017) reports:

"They are a dream of researchers but perhaps a nightmare for highly skilled computer programmers: artificially intelligent machines that can build other artificially intelligent machines ... Jeff Dean, one of Google's leading engineers, spotlighted a Google project called AutoML. ML is short for machine learning, referring to computer algorithms that can learn to perform particular tasks on their own by analyzing data. AutoML, in turn, is a machine-learning algorithm that learns to build other machine-learning algorithms. With it, Google may soon find a way to create 
A.I. technology that can partly take the humans out of building the A.I. systems that many believe are the future of the technology industry."

The singularity condition is placed on the robot sector alone, but it has economy-wide ramifications. If this condition fails, humans can never be displaced in the production of robots, and are always guaranteed a positive share of national income. For either some sectors of the economy are automated, in which case the robot sector becomes active, and humans must obtain a positive share of value added in the robot sector. Or there is no automation anywhere, in which case humans are not displaced in any sector, and the standard theory applies. Therefore, in the absence of singularity, there is a route by which the benefits of physical capital accumulation could persistently flow to humans.

Our paper also takes note of two other escape routes from the dismal conclusion of an ever-falling labor share: non-homothetic demand, or technical progress intrinsically biased in favor of humans.

Our emphasis throughout has been on the functional distribution of income. Whether a household remains on par with the economy will depend on whether they can become capital owners, or move into sectors where humans are more efficient relative to robots. We believe the former route to hold more hope than the latter. So - for a stable personal distribution - we reiterate the extreme importance of universal financial education. To share the gains from growth in the long run, humans must learn to own the means of production by owing and accumulating non-human capital, even as the relative power of their natural endowment - labor — is eroded over time. Finally, the simplicity and tractability of the model may allow it to be useful in analyzing effects of fiscal policies such as capital taxes, education subsidies, universal basic income or other interventions to address the distributional consequences of automation.

\section{REFERENCES}

D. Acemoglu and J. Robinson (2015), “The Rise and Decline of General Laws of Capitalism,” Journal of Economic Perspectives, 29(1), 3-28. 
D. Acemoglu and P. Restrepo (2018), “The Race Between Man and Machine: Implications of Technology for Growth, Factor Shares and Employment," American Economic Review, 108(6): 1488-1542.

(2019), “Automation and New Tasks: How Technology

Displaces and Reinstates Labor," Journal of Economic Perspectives, 33(2): 3-30.

P. Aghion, B. Jones, and C. Jones (2019), “Artificial Intelligence and Economic Growth," in Ajay Agrawal, Joshua Gans and Avi Goldfarb (eds), The Economics of Artificial Intelligence: An Agenda, National Bureau of Economic Research.

K.J. Arrow (1951), "Alternative Proof of the Substitution Theorem for Leontief models in the General Case". In Activity Analysis of Production and Allocation, ed. T.C. Koopmans. New York: John Wiley.

D. Autor, D. Dorn, L.F. Katz, C. Patterson and J. van Reenen (2017), “Concentrating on the Fall of the Labor Share," American Economic Review Papers and Proceedings, 107(5), 180-185.

J. Azar and X. Vives (2018), "Oligopoly, Macroeconomic Performance, and Competition Policy," mimeo., IISE Business School, Barcelona.

A. Banerjee and A. Newman (1993), "Occupational Choice and the Process of Development.” Journal of Political Economy 101, 274-298.

J.I. Bernstein and M.I. Nadiri (1988), "Interindustry R\&D Spillovers, Rates of Return, and Production In High-Tech Industries," American Economic Review - AEA Papers and Proceedings, 78, No. 2, pp. 429-434, May 1988.

R. Chirinko and D. Mallick (2014), “The Substitution Elasticity, Factor Shares, Long Run Growth and the Low Frequency Panel Model," Working Paper, University of Illinois at Chicago.

D. Comin, A. Danieli and M. Mestieri (2019), "Income-Driven Labor Market Polarization," Working Paper. 
G. Eggertsson, J. Robbins, and E.G. Wold (2018), “Kaldor and Piketty's Facts: The Rise of Monopoly Power in the United States," mimeo.

O. Galor and J. Zeira (1993), "Income Distribution and Macroeconomics.” Review of Economic Studies 60, 35-52.

S. Grossman and O. Hart (1979), "A Theory of Competitive Equilibrium in Stock Market Economies," Econometrica 47, 293-330.

G. Gutiérrez and T. Philippon (2017), ““‘Declining Competition and Investment in the U.S," mimeo., NYU Stern.

W. Johnson (2018), "Economic Growth and the Evolution of Comparative Advantage in an Occupation-Based Network of Industries," $\mathrm{PhD}$ dissertation, Department of Economics, Boston University.

L. Karabarbounis and B. Neiman (2014), "The Global Decline of the Labor Share," Quarterly Journal of Economics, 129(1): 61-103.

L. Ljungqvist (1993), "Economic Underdevelopment: The Case of Missing Market for Human Capital," Journal of Development Economics 40, 219-239.

L. Makowski (1980), "Perfect Competition, the Profit Criterion, and the Organization of Economic Activity," Journal of Economic Theory 22, 222-42.

G. Mankiw (2015), "Yes $r>g$. So What?" American Economic Review (Papers and Proceedings) 105, 43-47.

D. Mookherjee and D. Ray (2002), "Is Equality Stable?," American Economic Review 92 (Papers and Proceedings), 253-259.

D. Mookherjee and D. Ray (2003), "Persistent Inequality," Review of Economic Studies 70, 369-394.

D. Mookherjee and D. Ray (2010), "Inequality and Markets: Some Implications of Occupational Diversity," American Economic Journal: Microeconomics 2, 38-76. 
J. P. Neary (2003), “Globalization and Market Structure," Journal of the European Economic Association 1, 245-271.

D. Ray (2015), “Nit-Piketty: A Comment on Thomas Piketty's Capital in the Twenty First Century," CESifo Forum 16 (1), 19-25.

P. A. Samuelson (1951) "Abstract of a Theorem concerning Substitutability in Open Leontief Models". in Activity Analysis of Production and Allocation, ed. T.C. Koopmans. New York: John Wiley.

S. Santens (2016), “Robots Will Take Your Job,” The Boston Globe, February 24.

H. Uzawa (1961-2), “On a Two-Sector Model of Economic Growth,” Review of Economic Studies 29, 40-47.

J. von Neumann (and A. Burns) (1966), Theory of Self-Reproducing Automata, University of Illinois Press. 